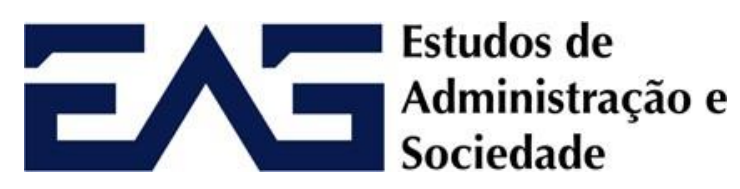

ISSN 2525-9261

\title{
EDITORIAL
}

\section{Saldos da balbúrdia}

Esta edição da revista Estudos de Administração e Sociedade marca o início das comemorações da passagem do décimo aniversário de criação do Programa de Pósgraduação em Administração (PPGAd) da Universidade Federal Fluminense - UFF. Antecipa a realização de eventos previstos para 2020 e 2021 e oferece a oportunidade de permitir, desde logo, o congraçamento da nossa comunidade acadêmica com o campo da Administração, em particular, e o das Ciências Sociais Aplicadas, em geral. Tal é a missão deste periódico, que se afirma como órgão de veiculação de conhecimento novo em nossas áreas de atuação.

Como número especial comemorativo, permitiu-se uma pequena transgressão nas boas práticas recomendadas às publicações científicas, qual seja, a necessidade de evitar a excessiva endogenia, quer dizer, a publicação de textos dos membros do próprio programa de pós-graduação. Traz, assim, artigos científicos de mestres egressos do PPGAd, assinados em alguns casos, sozinhos, e em outros, em coautoria com seus orientadores. Alguns artigos nasceram das dissertações; outros são trabalhos de qualidade elaborados durante o cumprimento dos créditos dos então estudantes. Em ambos os casos, todos os textos passaram por revisões minuciosas (peer review e blind review), obedecendo a critérios de rigor e relevância.

Também se persistiu na busca da interdisciplinaridade e da internacionalização. Os temas apresentados, para além do foco na Administração, tangenciam os campos da Ciência Política e da Sociologia, oferecendo destaque mais uma vez ao Pensamento Social Brasileiro. Entre os autores, para além de profissionais engajados em funções de ensino, pesquisa e prática da gestão no Brasil, encontra-se uma mestre em Administração egressa do programa que hoje milita como pesquisadora em um programa de pós-graduação da Hungria, fazendo a aproximação do trabalho do PPGAd com centros de pesquisa da Europa central.

A edição é aberta com um texto do prof. Cláudio Gurgel, "O PPGAd faz dez anos" que chefiava o Departamento de Administração da UFF, Campus do Valonguinho, à época da criação do PPGAd e foi o grande responsável pela sua idealização e por sua implantação. $\mathrm{O}$ artigo oferece um quadro bastante elucidativo das razões que fizeram a UFF instituir o novo programa de pós-graduação, as resistências encontradas e o acolhimento da proposta no ambiente universitário do estado do Rio de Janeiro e até de outras partes do Brasil.

O artigo "Educação problematizadora e políticas inclusivas: uma avaliação sobre a formação em Administração das Universidades fluminenses", de autoria de Analice Valdman de Miranda, egressa do PPGAd, e de Carlyle Tadeu Falcão de Oliveira, professor do Programa, centra-se na discussão sobre a inclusão das pessoas com deficiências e tem por objetivo verificar junto às escolas públicas de Administração da região metropolitana do Rio de Janeiro como elas procuram formar seus alunos para atuarem enquanto gestores inclusivos.

Fabio Moita Louredo, também egresso do PPGAd, apresenta o artigo "Repensando as bases da administração pública brasileira: contribuições de Guerreiro Ramos sob o olhar decolonial" em que oferece uma instigante análise do aporte da obra do grande sociólogo baiano à discussão sobre as bases da administração pública brasileira, a partir de uma perspectiva em que foi pioneiro - a crítica aos colonialismo intelectual, 


\section{ש $\begin{aligned} & \text { Estudos de } \\ & \text { Administração e } \\ & \text { Sociedade }\end{aligned}$}

ISSN 2525-9261

agora chamado de pensamento pós-colonial.

O artigo de Talita Almeida de Campos Nascimento Thompson Coelho e Sidinei Rocha de Oliveira, autores que se identificam como egressa e ex-professor do PPGAd, intitulado "Os sentidos do trabalho no serviço público: uma perspectiva geracional", tem por objetivo analisar os sentidos do trabalho para servidores públicos de diferentes gerações de técnico-administrativos da Universidade Federal do Estado do Rio de Janeiro (UNIRIO), a partir de entrevistas realizadas com servidores técnico-administrativos das duas gerações identificadas na pesquisa, valendo-se de análise de conteúdo do material coletado.

Finalmente, as pesquisadoras Cláudia Jordão e Agatha Justen escrevem sobre "A cidadania na reforma do Estado brasileiro: discurso oficial e percepção empírica", onde pretendem expor percepções de membros de programas de pós-graduação em Administração sobre a reforma ocorrida nos anos 1990 e em particular sobre o exercício da cidadania.

São trabalhos de elevada qualidade, comprovada pela apresentação em eventos de caráter nacional e internacional, que são mobilizados, em caráter excepcional, para ilustrar a excelência da produção acadêmica do PPGAd. O próximo número traz os demais artigos que nasceram dessa produção e que foram criteriosamente avaliados pelos nossos pares mobilizados, em sua grande maioria, entre scholars não pertencentes aos quadros da UFF.

Boa leitura.

Frederico Lustosa da Costa 